\title{
Comparative analysis of thermoelectric elements optimum geometry between photovoltaic-thermoelectric and solar thermoelectric
}

Guiqiang Li*

Guiqiang.Li@hull.ac.uk

Samson Shittu

Xiaoli Ma

Xudong

xudong.zhao@hull.ac.uk

School of Engineering, University of Hull, United Kingdom

${ }^{*}$ Corresponding author.

${ }^{* *}$ Corresponding author

Abstract

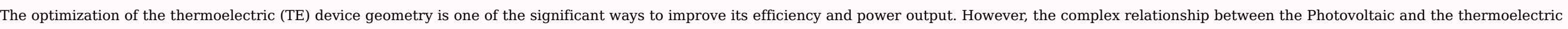

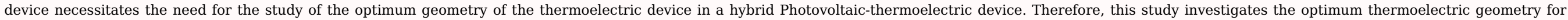

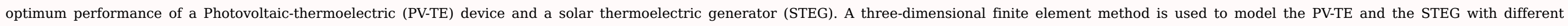

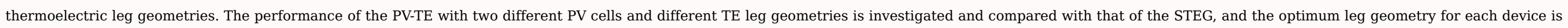

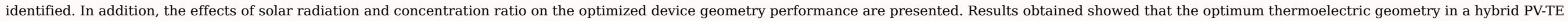

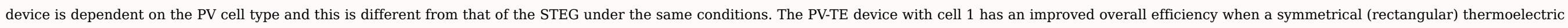

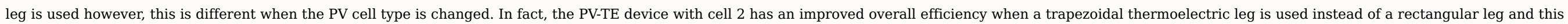

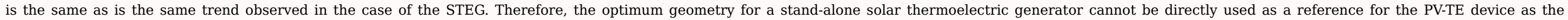

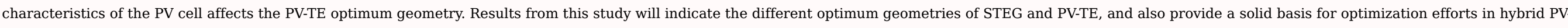
TE devices.

Keywords: PV-TE; STEG; Trapezoidal leg; Solar irradiation; Optimum geometry

\section{Nomenclature}

Area, $\mathrm{m}^{2}$

$A_{s}$

Area of SSA, $\mathrm{m}^{2}$

Concentration ratio 
Radiative heat transfer coefficient, $W\left(m^{2} \cdot K\right)$

$h_{\text {wind }}$

Convective heat transfer coefficient, $W\left(m^{2} \cdot K\right)$

$k$

Thermal conductivity, $W /(m K)$

L

TE Leg Height, $m$

$\mathrm{P}$

Power output, W

$Q_{\text {flow }}$

Thermal energy, $\mathrm{W}$

$R_{A}$

Cross-sectional area ratio of TE hot and cold junctions

$R_{L}$

Load resistance on TEG, $\Omega$

$T$

Temperature, $\mathrm{K}$

$T_{p}$

PV Temperature, $\mathrm{K}$

$T_{r}$

Reference Temperature, $\mathrm{K}$

$u_{\mathrm{w}}$

Wind Velocity, m/s 
Absorptivity

$\beta_{p V}$

PV temperature coefficient, $\mathrm{K}^{-1}$

Efficiency

$\eta_{r}$

Reference Efficiency

$\eta_{\text {opt }}$

Optical Efficiency

Subscripts

Ambient

C

Cold side

$\mathrm{H}$

Hot side

n-type

$\mathrm{p}$

p-type

Abbreviations

PV

Photovoltaic

TE

Thermoelectric

SSA

Solar Selective Absorber 


\section{Introduction}

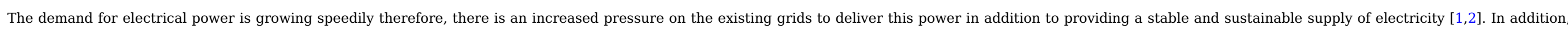

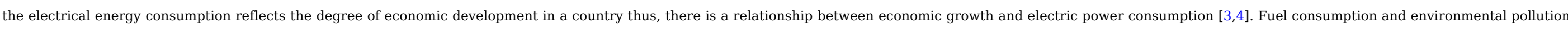

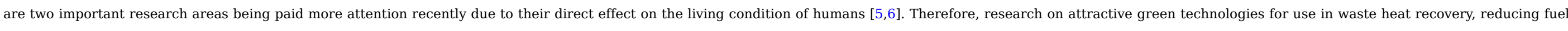

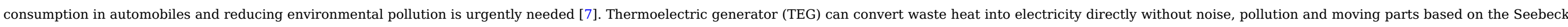

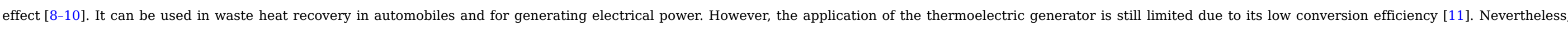

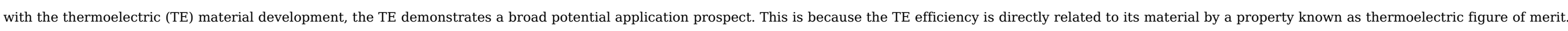

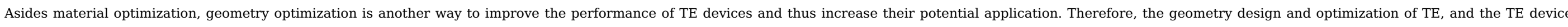

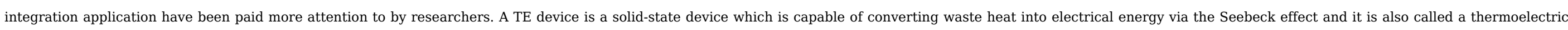

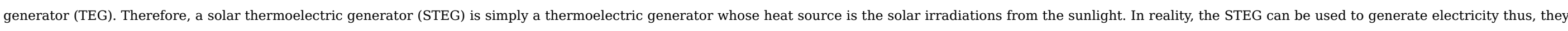

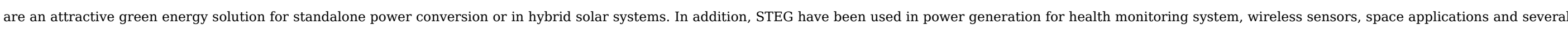

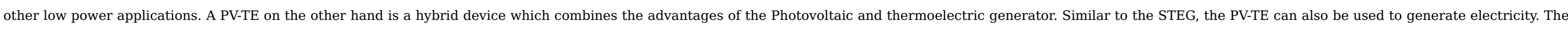

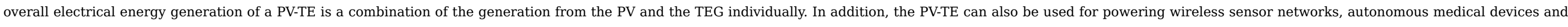
for terrestrial and space applications.

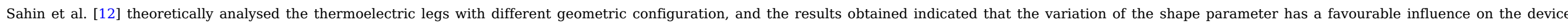

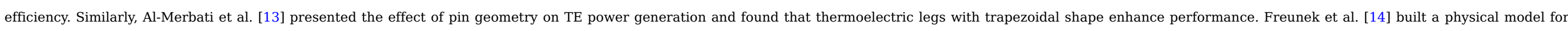

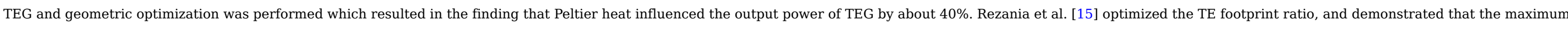
output and cost-performance are achieved at $\mathrm{An} / \mathrm{Ap}<1$.

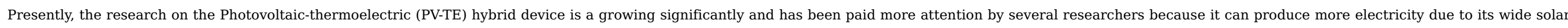

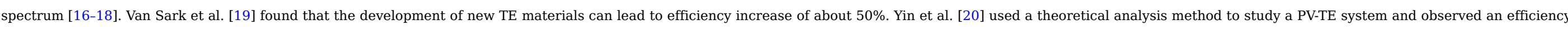

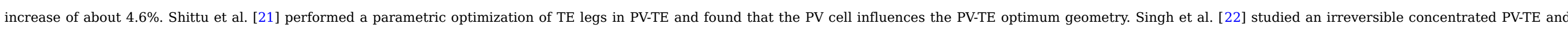

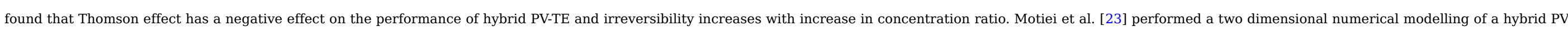

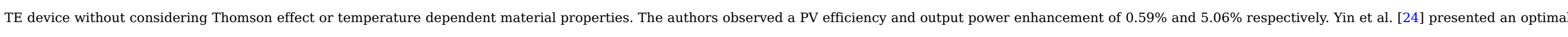

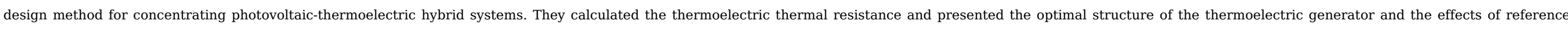

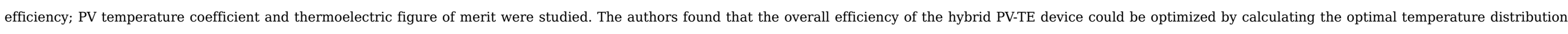

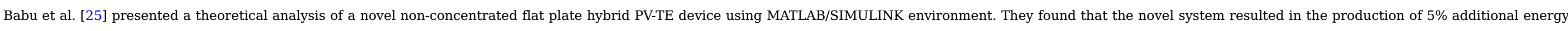

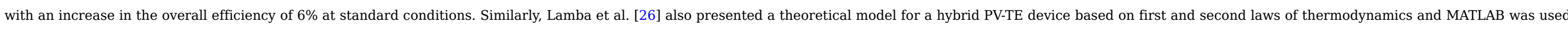

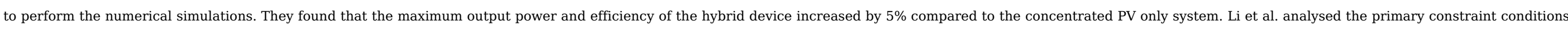

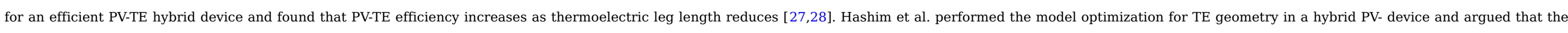
thermoelectric element dimension in the PV-TE has a significant influence on the overall hybrid device power output [29].

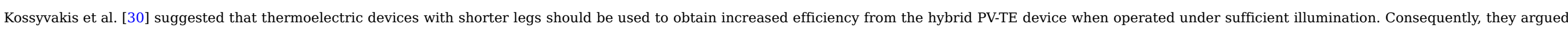

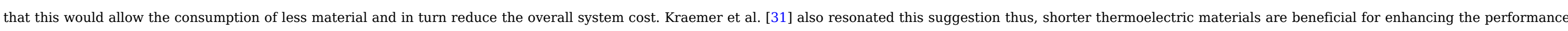

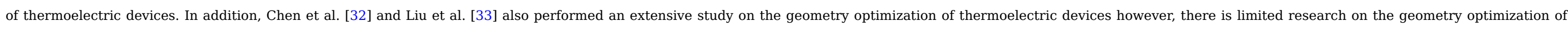

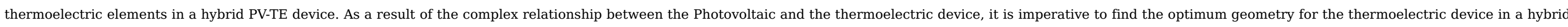




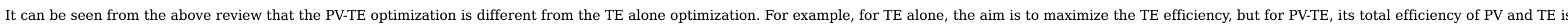

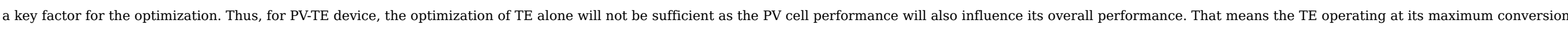
efficiency will not definitely lead to the maximum electrical efficiency of the PV-TE. In other words, the optimized geometry of TEG may not be suitable for PV-TE optimization.

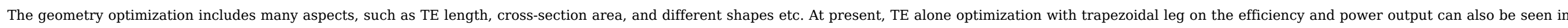

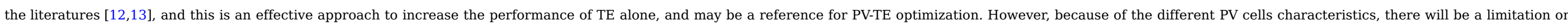

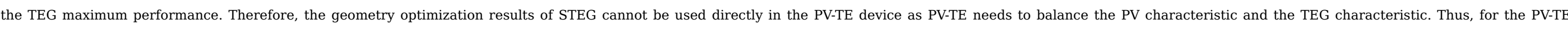

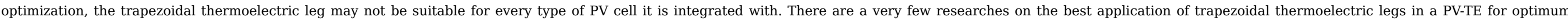
performance and more so, there are only a handful of research on the comparison of PV-TE and STEG employing trapezoid leg or rectangular leg.

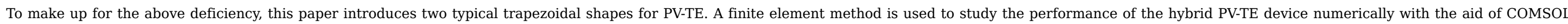

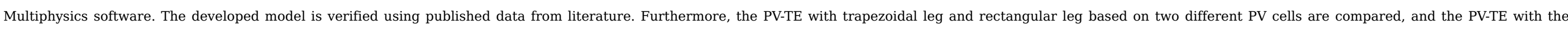

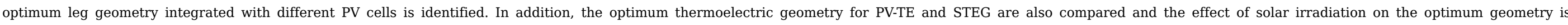

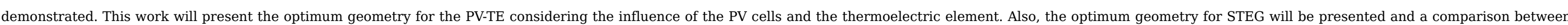

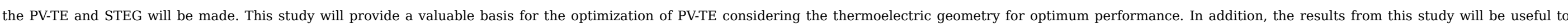
researchers interested in optimizing PV-TE and STEG.

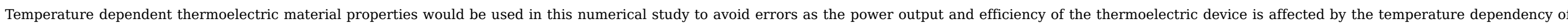

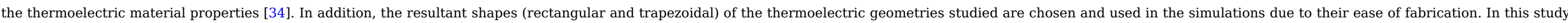

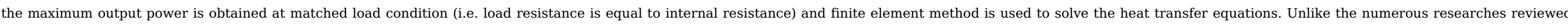

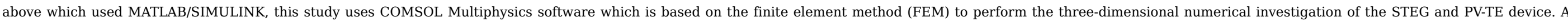

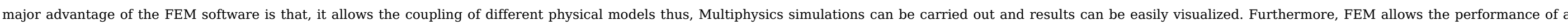

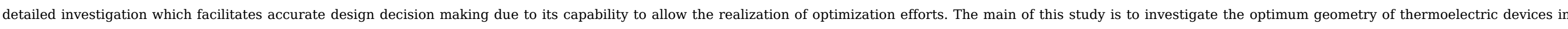

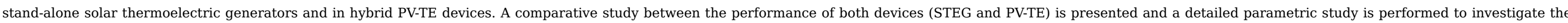
influence of geometric parameters (leg length, cross sectional area) and environmental parameters (solar radiation, concentration ratio) on the performance of STEG and PV-TE device.

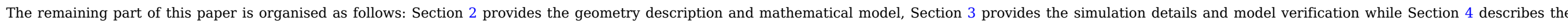
results obtained and analysis of the results. Lastly, Section 5 provides the main conclusions drawn from this study.

\section{Geometry description and mathematical model}

The detailed description of the PV-TE and STEG investigated in this study will be presented in this section and the mathematical model used in performing the numerical simulation will also be presented.

\subsection{Geometry description}

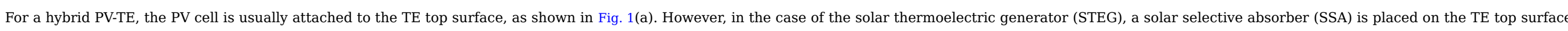

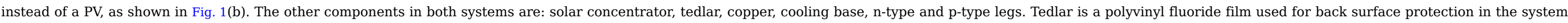

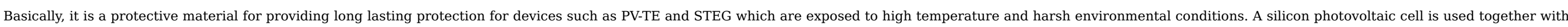

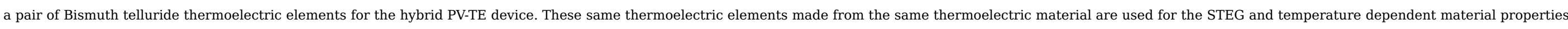

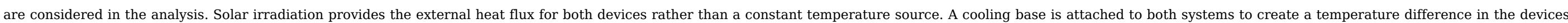
and improve their electrical performance. 


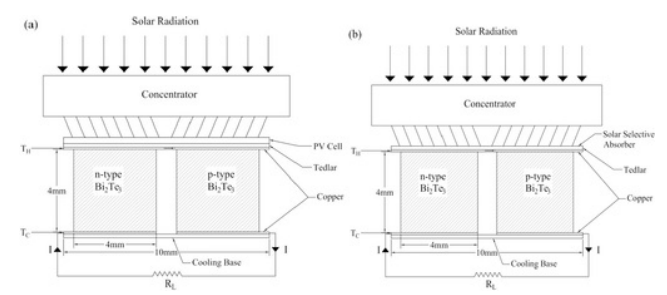

Fig. 1 Schematic diagram of (a) hybrid PV-TE and (b) STEG.

alt-text: Fig. 1

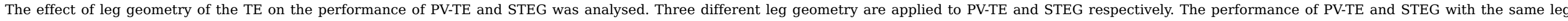

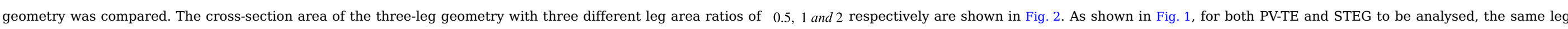

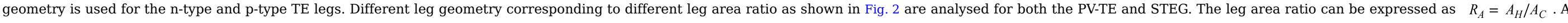

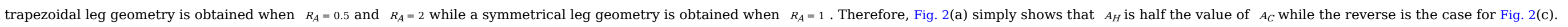

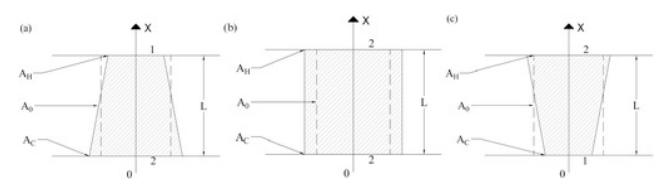

Fig. 2 Cross sectional area geometry for (a) $R_{A}=0.5$, (b) $R_{A}=1$ and (c) $R_{A}=2$

alt-text: Fig. 2

This research is carried out to analyse the steady-state performance of the PV-TE and STEG devices. The following assumptions are made to simplify the models:

- Heat transfer is only in one dimension

- Uniform solar thermal distribution and temperature distribution is assumed on the surface of the PV and STEG.

- Constant room temperature of $298 \mathrm{~K}$ is maintained at the cold side of devices.

- All surfaces except the upper surface (hot) and lower surface(cold) are considered to be thermally insulated.

- The geometry of the p-type and n-type thermoelectric elements are identical.

- The thermoelectric elements are connected in series electrically and in parallel thermally.

- Area of the PV is the same with the area of the solar selective absorber.

\subsection{Mathematical model}

The mathematical equations used in numerically studying the performance of the devices are presented in this section. Three-dimensional finite element analysis is used in this study.

\subsubsection{Finite element model}

Finite element method is employed to solve the temperature and electric field equations in the thermoelectric unit. The coupling equations for the temperature $T$ and electric potential $V$ are given as [35]:

$\nabla(k \nabla T)+\rho \mathbf{J}^{2}-T \mathbf{J} \cdot\left[\left(\frac{\partial \alpha}{\partial T}\right) \nabla T+(\nabla \alpha)_{T}\right]=0$

$\nabla \cdot \mathbf{J}=0$

$\mathbf{J}=-\sigma\left[\nabla\left(\frac{\mu}{e}+V\right)+\alpha \nabla T\right]$ 


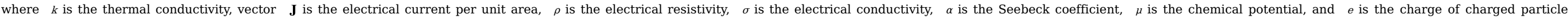

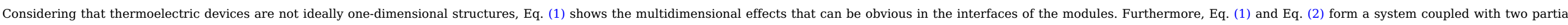

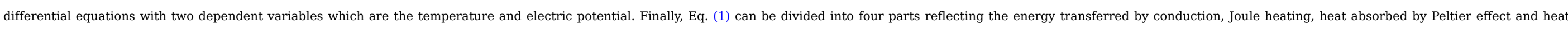

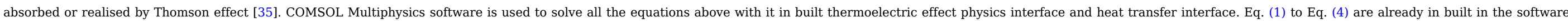
therefore, they need no physical derivation.

In this research, temperature dependent thermoelectric material properties are used and they are given as [36]:

$k_{n}=\left(0.0000334545 \times T^{2}-0.023350303 \times T+5.606333\right) \mathrm{W} / \mathrm{m} \cdot \mathrm{K}$

$k_{p}=\left(0.0000361558 \times T^{2}-0.026351342 \times T+6.22162\right) \mathrm{W} / \mathrm{m} \cdot \mathrm{K}$

$\alpha_{n}=\left(0.001530736 \times T^{2}-1.08058874 \times T-28.338095\right) \times 10^{-6} \mathrm{~V} / \mathrm{K}$

$\alpha_{p}=\left(-0.003638095 \times T^{2}+2.74380952 \times T-296.214286\right) \times 10^{-6} \mathrm{~V} / \mathrm{K}$

$\sigma_{n}=\left(0.01057143 \times T^{2}-10.16048 \times T+3113.71429\right) \times 10^{2} \mathrm{~S} / \mathrm{m}$

$\sigma_{p}=\left(0.015601732 \times T^{2}-15.708052 \times T+4466.38095\right) \times 10^{2} S / m$

where the subscript $n$ denotes $\mathrm{n}$-type thermoelectric element and $p$ denotes p-type thermoelectric element.

The mathematical model that describes the leg geometry as shown in Fig. 2 can be written as [13]:

$A(x)=\frac{A_{H}-A_{C}}{L} x+A_{C}$

where $A(x)$ is the cross-sectional area of the TE legs along path $x, A_{C}$ is the cross-sectional area of the leg cold side, $A_{H}$ is the cross-sectional area of the leg hot side and $L$ is the leg height. The leg area ratio is given as

$R_{A}=\frac{A_{H}}{A_{C}}$

Substituting Eq. (12) into Eq. (11) results in

$A(x)=A_{0}\left[1+2 \frac{R_{A}-1}{R_{A}+1}\left(\frac{x}{L}-\frac{1}{2}\right)\right]$

where $A_{0}$ is the cross-sectional area of the uniform leg.

Along the path $x$, the leg heat transfer rate can be expressed as

$\dot{Q}=-k A(x) \frac{d T}{d x}$

Assuming the heating condition is steady and the leg surfaces are isolated, Eq. (14) can be re-written as

$\dot{Q} \int_{0}^{L} \frac{d x}{A(x)}=-k \int_{T_{C}}^{T_{H}} d T$

Substituting Eq. (3) into Eq. (5) and performing integration results in,

$\dot{Q}=\frac{2 k \frac{A_{0}}{L}\left(\frac{R_{A}-1}{R_{A}+1}\right)}{\ln \left(R_{A}\right)}\left(T_{H}-T_{C}\right)$

The overall thermal conductance of the TE leg can be expressed as 
$K_{\operatorname{leg}}=\frac{2 k \frac{A_{0}}{L}\left(\frac{R_{A}-1}{R_{A}+1}\right)}{\ln \left(R_{A}\right)}$

The overall electrical resistance of the TE leg can be expressed as

$$
R_{\text {leg }}=\frac{1}{2 k_{e} \frac{A_{0}}{L}\left(\frac{R_{A}-1}{R_{A}+1}\right)} \ln \left(R_{A}\right)
$$

\subsubsection{Hybrid PV-TE model and STEG model}

Two mathematical models are used to describe the performance of the hybrid PV-TE and STEG respectively.

(a) Hybrid PV-TE model

The energy balance equation in the hybrid PV-TE system can be written as [18],

$E_{\text {in }}=E_{p v}+h_{\text {rad }} A\left(T_{p}-T_{\text {sky }}\right)+h_{\text {wind }} A\left(T_{p}-T_{a}\right)+Q_{\text {flow }}$

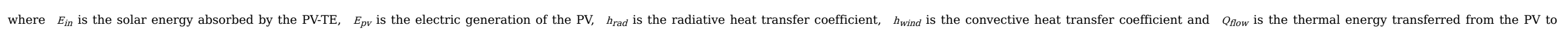
the TE.

Absorbed solar energy can be written as, $E_{\text {in }}=C G A \alpha_{c}$

where $C$ is the solar concentration ratio, $G$ is the solar irradiation, $A$ is the $\mathrm{PV}$ area and $\alpha_{C}$ is the PV absorptivity.

$\mathrm{PV}$ electrical can be defined as [37],

$E_{p v}=C G A \alpha_{c} \eta_{r}\left[1-\beta_{p v}\left(T_{p}-T_{r}\right)\right]$

where $T_{p}$ is the $\mathrm{PV}$ temperature, $\beta_{p V}$ is the PV temperature coefficient, $\eta_{r}$ is the PV reference efficiency at standard conditions and $T_{r}$ is the reference temperature.

$h_{\text {wind }}$ is given as $[38,39]$,

$h_{\text {wind }}=2.8+u_{w}$

$h_{\text {rad }}$ is given as,

$h_{\text {rad }}=\varepsilon \sigma\left(T_{p}^{2}+T_{\text {sky }}^{2}\right)\left(T_{p}+T_{\text {sky }}\right)$

where $\varepsilon$ is the PV emissivity and $\sigma$ is the Stefan-Boltzmann constant.

$T_{\text {sky }}=0.0552 T_{a}^{1.5}$

where $T_{a}$ is the ambient temperature and $T_{s k y}$ is temperature of the sky.

$Q_{\text {flow }}$ is given as,

$Q_{\text {flow }}=Q_{H}$

where $Q_{H}$ is the energy flowing into the hot side of the TE and can be written as [40],

$Q_{H}=\alpha T_{H} I+k \cdot T-\frac{1}{2} I^{2} R_{T E}$

where $T_{H}$ is the TE hot side temperature, $I$ is the electrical current and $R_{T E}$ is the internal electrical resistance.

(24)

(25) 
The $Q_{C}$ can be written as,

$$
Q_{C}=\alpha T_{C} I+k \cdot T+I^{2} R_{T E}
$$

The power output of the TEG is given as,

$P_{T E}=I^{2} R_{L}$

where $R_{L}$ is the load resistance.

The efficiency of the TEG is given as,

$\eta_{T E}=\frac{P_{T E}}{Q_{H}}$

Therefore, the overall efficiency of the PV-TE can be written as follow,

$\eta_{P V-T E}=\frac{E_{p v}+P_{T E}}{C G A}$

(b) STEG model

The input solar energy absorbed at the surface of the STEG can be expressed as [41],

$$
Q_{\text {in }}=C G A_{s} \alpha_{s} \eta_{\text {opt }}
$$

where $A_{S}$ is the area of SSA (placed on surface of STEG), $\alpha_{S}$ is the STEG absorptivity and $\eta_{\text {opt }}$ is the optical efficiency which is assumed to be $100 \%$.

Similar to the PV-TE model described above, the radiative and convective heat losses are also considered in the STEG model and the equations are the same. $Q_{\text {rad }}=h_{\text {rad }} A_{s}\left(T_{p}-T_{s k y}\right)$

$Q_{c o v}=h_{\text {wind }} A_{s}\left(T_{p}-T_{a}\right)$

The efficiency of the TEG has been given in Eq. (29). Therefore, the overall efficiency of the STEG can be given as [42]

\section{Simulation and verification}

\subsection{Simulation details}

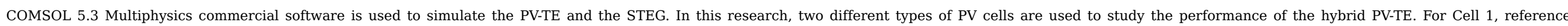

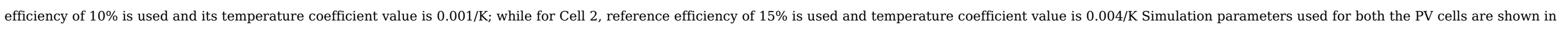

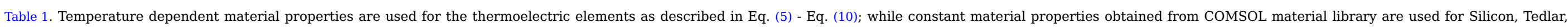
Copper and Alumina which are the other system components. The cross-sectional area of the SSA and that of the PV is assumed to be the equivalent to the cross-sectional area of the thermoelectric module.

Table 1 Simulation parameters.

\begin{tabular}{|c|c|c|c|c|}
\hline & Parameters & Symbol & Value & References \\
\hline SSA area & & $A_{s}$ & $0.0001 \mathrm{~m}^{2}$ & \\
\hline PV area & & $A$ & $0.0001 \mathrm{~m}^{2}$ & [27] \\
\hline
\end{tabular}

alt-text: Table 1 


\begin{tabular}{|c|c|c|c|}
\hline PV thickness & $T h_{P V}$ & $0.0003 \mathrm{~m}$ & [43] \\
\hline Tedlar thickness & $T h_{t e d}$ & $0.000175 \mathrm{~m}$ & [43] \\
\hline Copper thickness & $T h_{C o}$ & $0.0001 \mathrm{~m}^{2}$ & {$[44]$} \\
\hline TE area & $A_{T E}$ & $0.000016 \mathrm{~m}^{2}$ & \\
\hline TE height & $L$ & $0.004 \mathrm{~m}$ & \\
\hline SSA absorptivity & $\alpha_{s}$ & 0.93 & [45] \\
\hline PV absorptivity & $\alpha_{C}$ & 0.9 & [43] \\
\hline SSA emissivity & $\varepsilon_{S}$ & 0.8 & [45] \\
\hline PV emissivity & $\varepsilon$ & 0.8 & {$[44]$} \\
\hline Ambient temperature & $T_{a}$ & $298 \mathrm{~K}$ & {$[46]$} \\
\hline Solar irradiation & $G$ & $1000 \mathrm{~W} / \mathrm{m}^{2}$ & [46] \\
\hline Concentration ratio & $c$ & 4 & \\
\hline Wind velocity & $u_{W}$ & $1 \mathrm{~m} / \mathrm{s}$ & {$[44]$} \\
\hline Cell 1 reference efficiency (STC) & $\eta_{r}$ & $10 \%$ & [29] \\
\hline Cell 1 temperature coefficient & $\beta_{p V}$ & $0.001 \mathrm{~K}^{-1}$ & [29] \\
\hline Cell 2 reference efficiency (STC) & $\eta_{r}$ & $15 \%$ & [47] \\
\hline Cell 2 temperature coefficient & $\beta_{p V}$ & $0.004 \mathrm{~K}^{-1}$ & [47] \\
\hline Reference temperature & $T_{r}$ & $298 \mathrm{~K}$ & [29] \\
\hline
\end{tabular}

\subsection{Model validation}

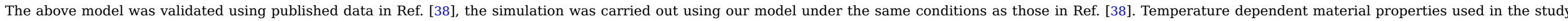

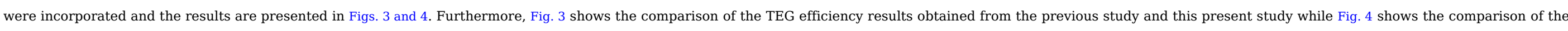

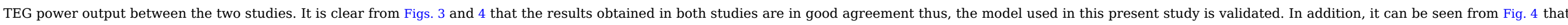

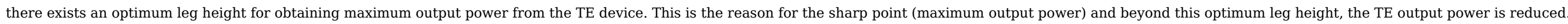




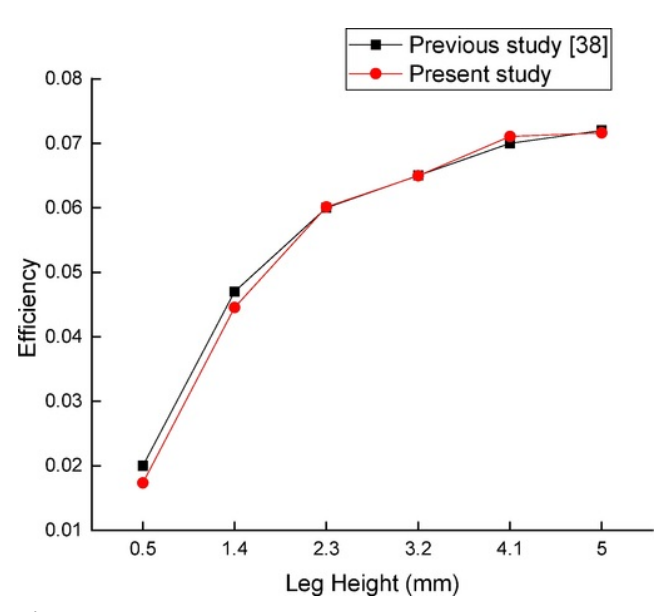

Fig. 3 TEG efficiency validation of previous study with present simulation. alt-text: Fig. 3

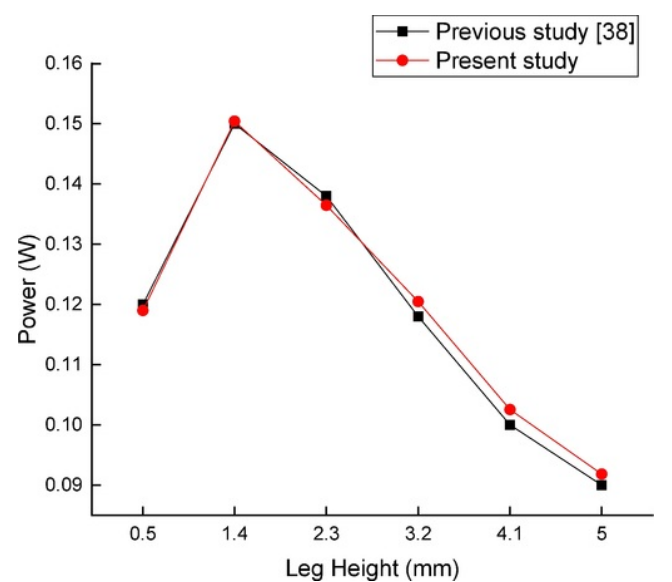

Fig. 4 TEG power validation of previous study with present simulation.

alt-text: Fig. 4

\section{Results and discussion}

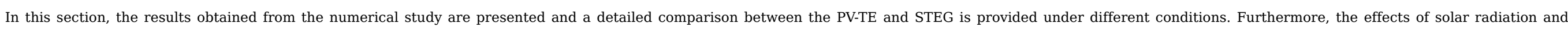
concentration ratio on the performance of both devices (STEG and PV-TE) are discussed.

\subsection{Detailed comparison of PV-TE and STEG}

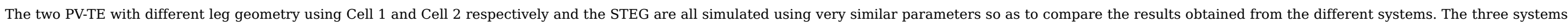
are analysed for the leg area ratio $R_{A}=0.5,1$ and 2 . The mesh diagrams of the PV-TE and STEG with different leg geometry are shown in Fig. 5. 


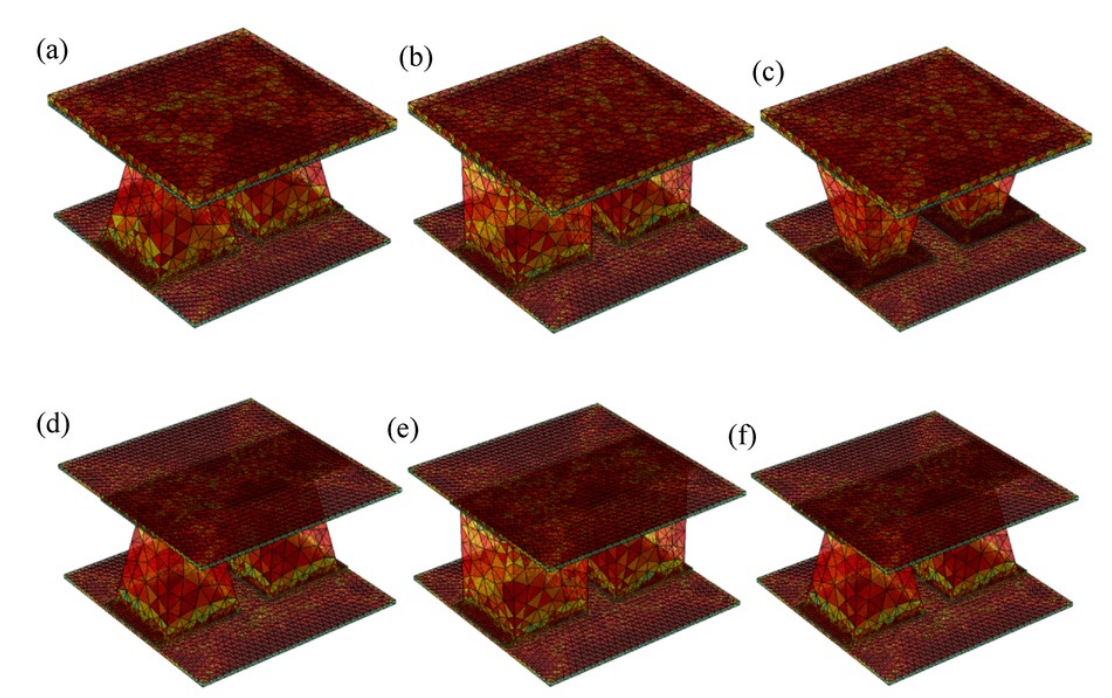

Fig. 5 Mesh diagrams of the PV-TE with trapezoidal and rectangular legs (a) $R_{A}=0.5$, (b) $R_{A}=1$, (c) $R_{A}=2$ and the STEG (d) $R_{A}=0.5$, (e) $R_{A}=1$, (f) $R_{A}=2$.

\section{alt-text: Fig. 5}

\subsubsection{Comparison for the condition of $R_{A}=0.5$}

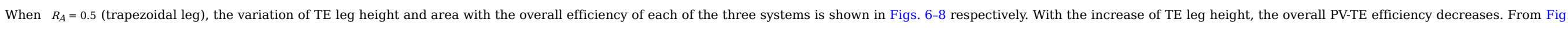

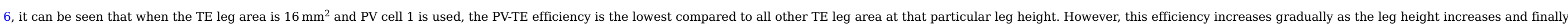

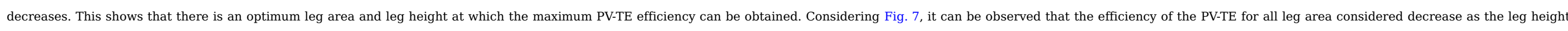
increases. This trend is different from that of Fig. 6, because of the difference in the characteristics of the PV cells used.

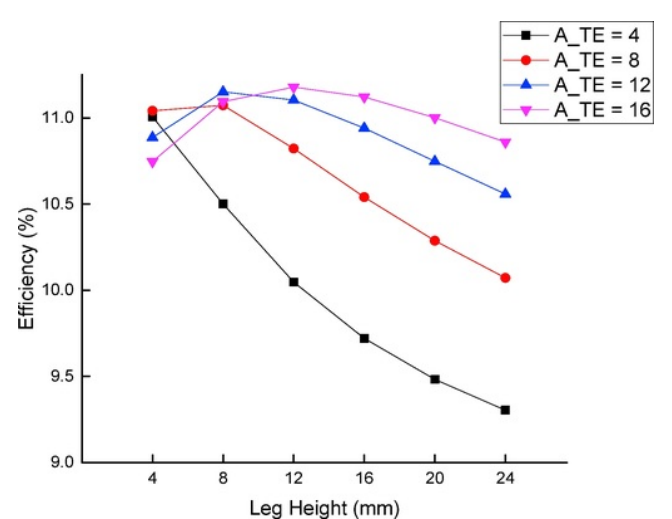

Fig. 6 Variation of overall efficiency of PV-TE with TE height and area increase using Cell 1, $R_{A}=0.5$

alt-text: Fig. 6 


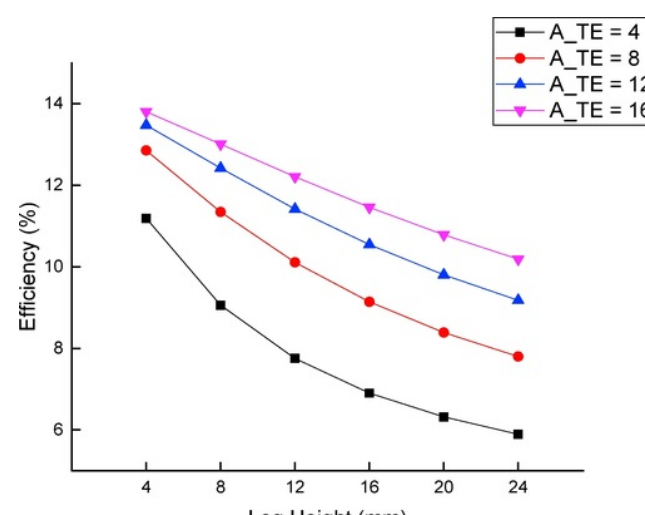

Leg Height (mm)

Fig. 7 Variation of overall efficiency of PV-TE with TE height and area increase using Cell $2, R_{A}=0.5$

\section{alt-text: Fig. 7}

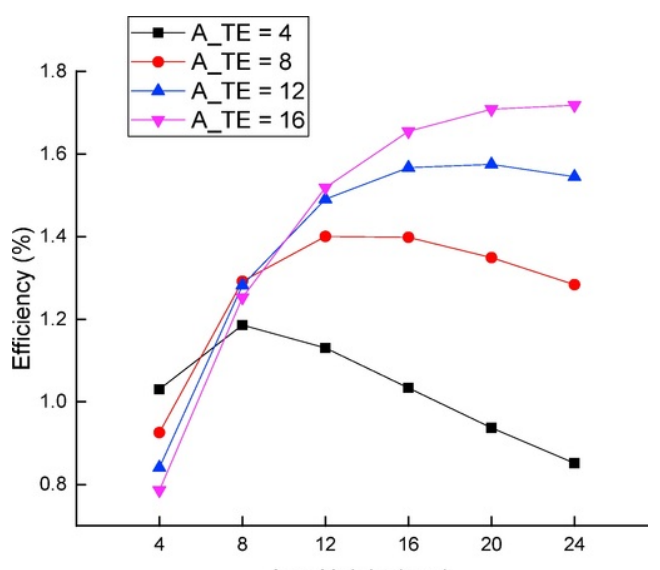

Leg Height (mm)

Fig. 8 Variation of STEG efficiency with TE height and area increase, $R_{A}=0.5$.

\section{alt-text: Fig. 8}

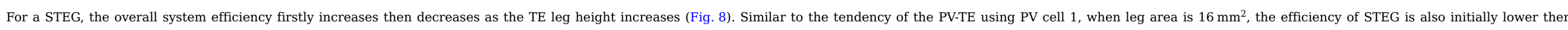

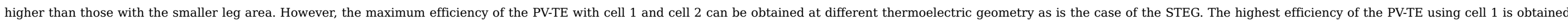

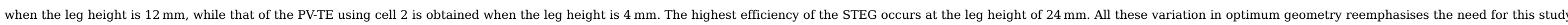

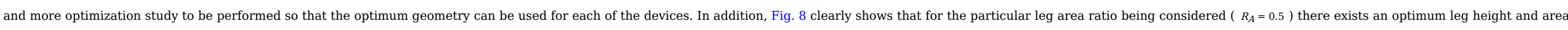

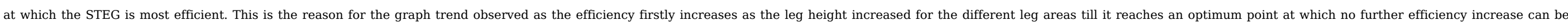
achieved thus, it starts decreasing.

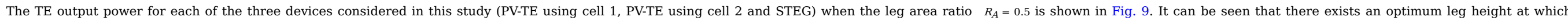

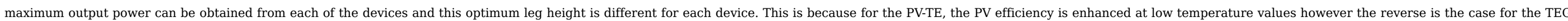

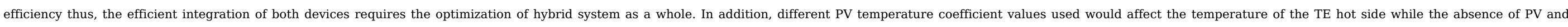
presence of SSA in the STEG would also cause the hot side temperature to be different. Consequently, there will be a different temperature difference in each system and the resulting TE output power will be different. 


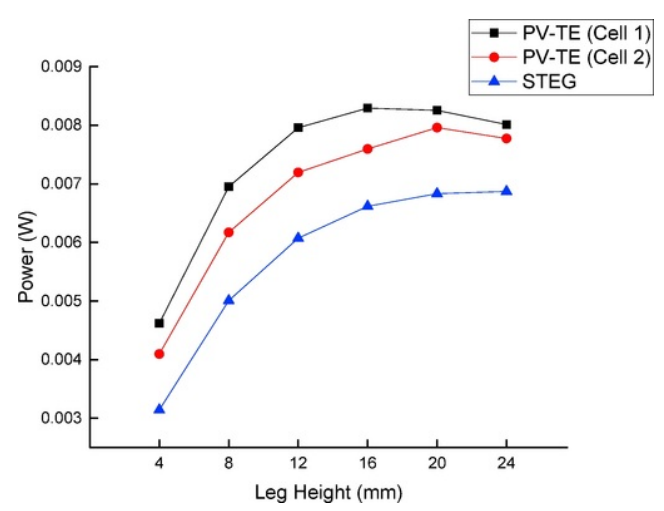

Fig. 9 TE output power in PV-TE Cell 1, PV-TE Cell 2 and STEG, $R_{A}=0.5$.

\section{alt-text: Fig. 9}

\subsubsection{Comparison for the condition of $R_{A}=1$}

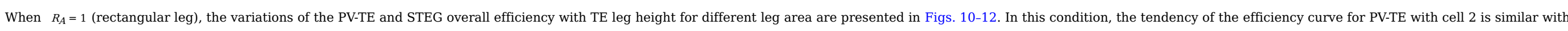

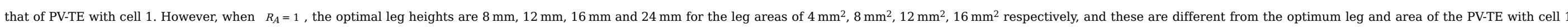

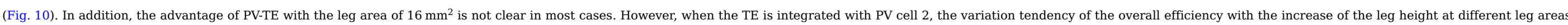
are the same as that with PV cell 1 (Fig. 11).

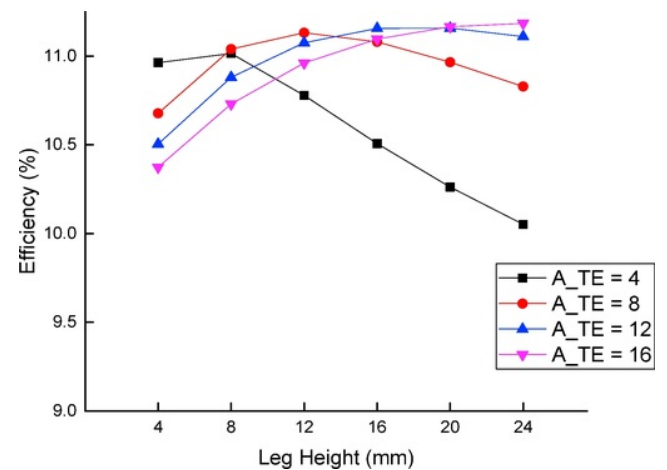

Fig. 10 Variation of overall efficiency of PV-TE with TE height and area increase using Cell $1, R_{A}=1$.

alt-text: Fig. 10 


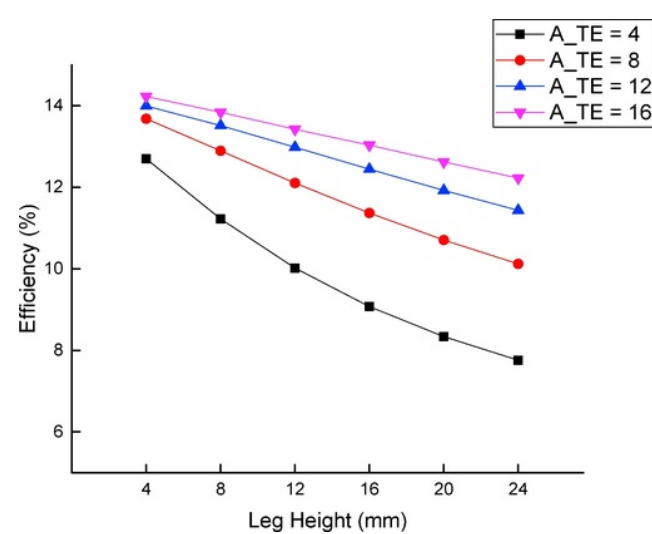

Fig. 11 Variation of overall efficiency of PV-TE with TE height and area increase using Cell 2, $R_{A}=1$.

alt-text: Fig. 11

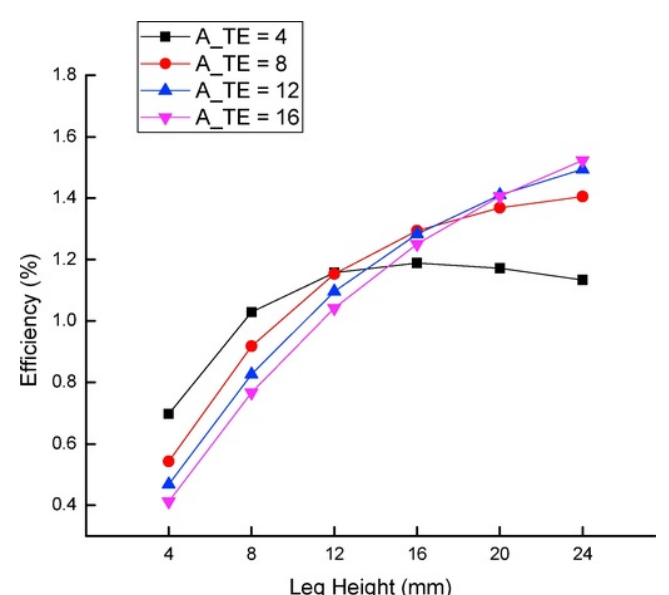

Fig. 12 Variation of STEG efficiency with TE height and area increase, $R_{A}=1$.

\section{alt-text: Fig. 12}

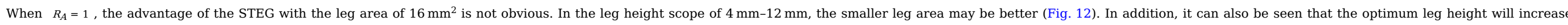
with the leg area rising. The variation of the TE output power in the different PV-TE and STEG is presented in Fig. 13 and it can be seen that with the increase of leg height, the outputs all show a rising trend. 


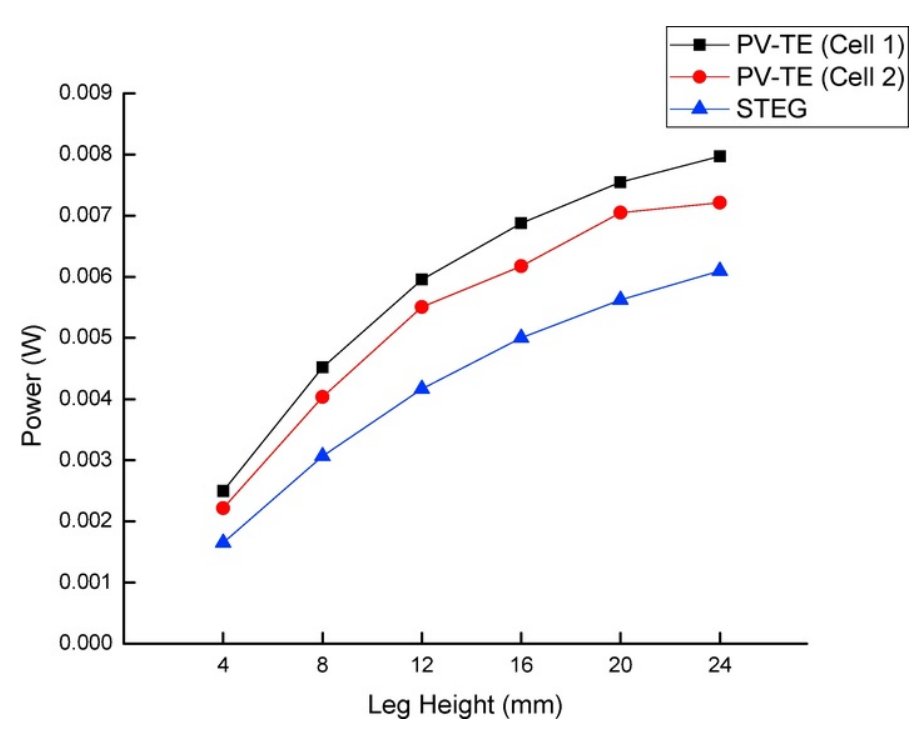

Fig. 13 TE output power in PV-TE Cell 1, PV-TE Cell 2 and STEG, $R_{A}=1$.

\section{alt-text: Fig. 13}

\subsubsection{Comparison for the condition of $R_{A}=2$}

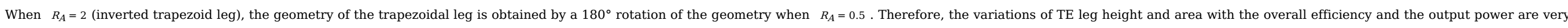
identical to the results with $R_{A}=0.5$.

\subsection{Overall efficiency comparison}

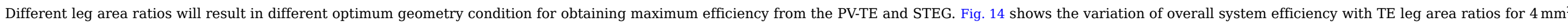

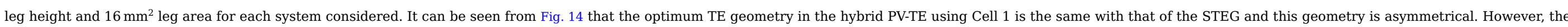

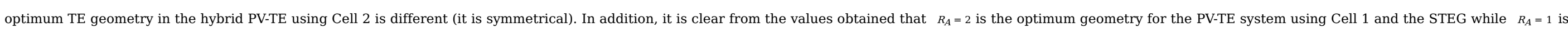
the optimum geometry for the PV-TE system using Cell 2.

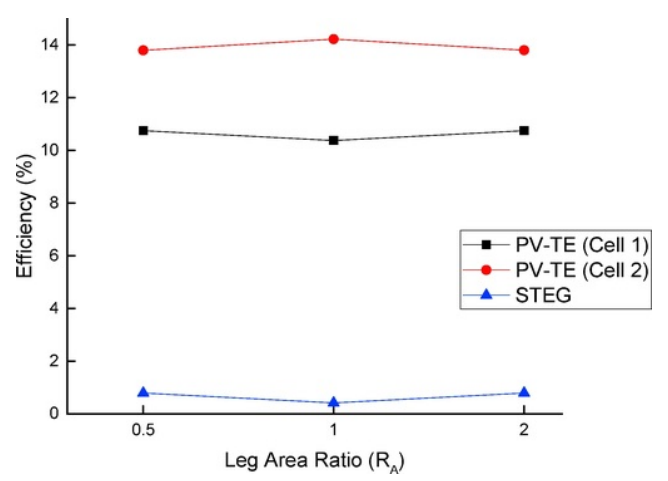

Fig. 14 Overall efficiency variation with leg area ratio. 


\subsection{Effect of solar radiation on optimum geometry}

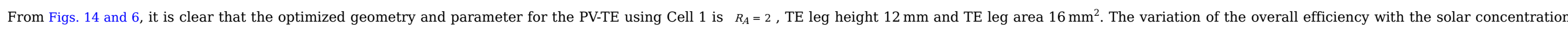

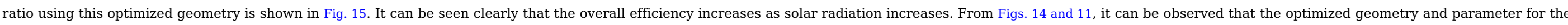

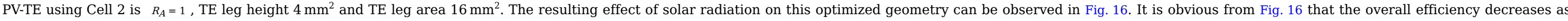

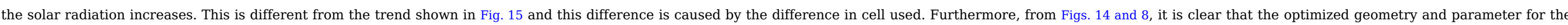

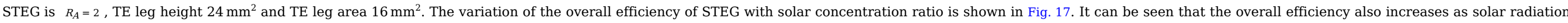
increases and this is similar to the trend observed in Fig. 15.

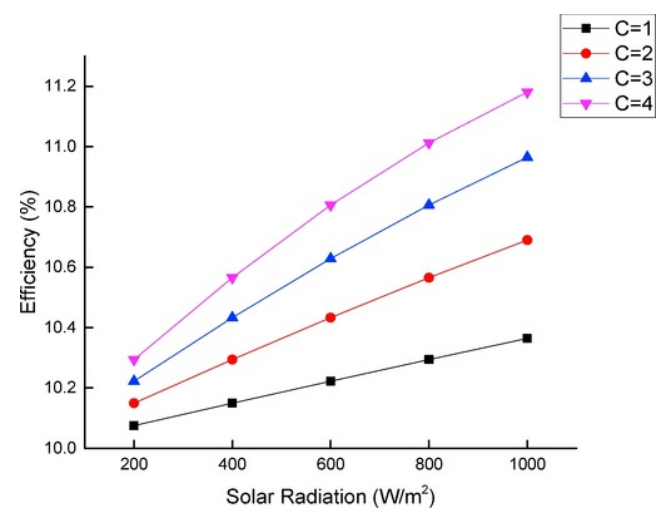

Fig. 15 Variation of overall efficiency of PV-TE using Cell 1 with solar radiation increase.

alt-text: Fig. 15

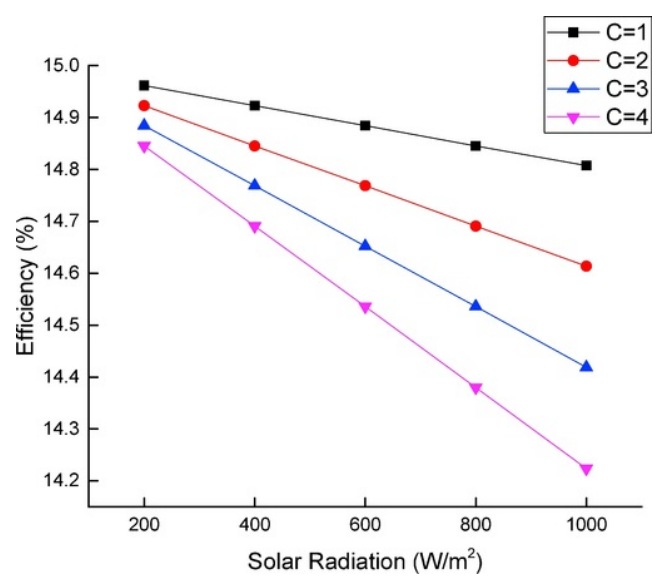

Fig. 16 Variation of overall efficiency of PV-TE using Cell 2 with solar radiation increase.

alt-text: Fig. 16 


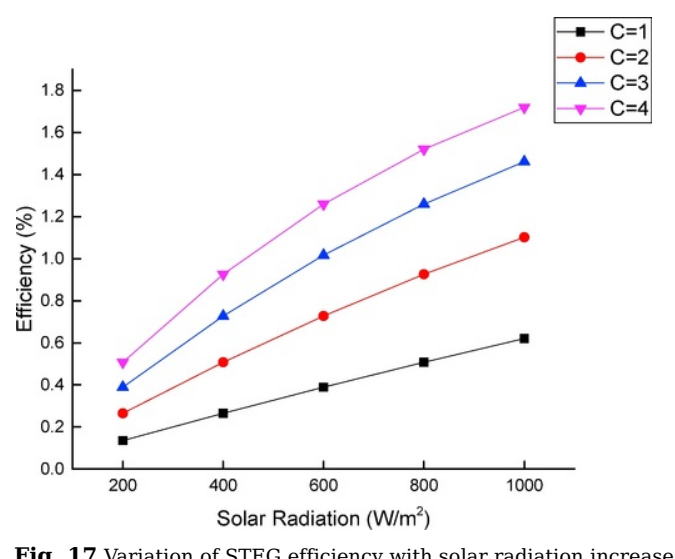

alt-text: Fig. 17

\section{Conclusion}

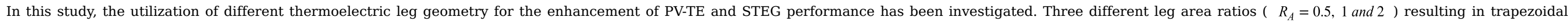

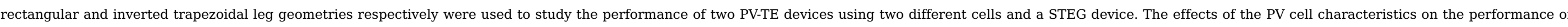

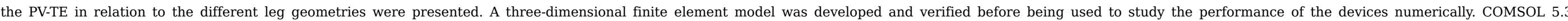

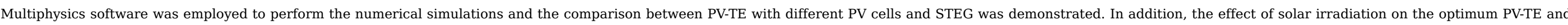
STEG geometry was analysed.

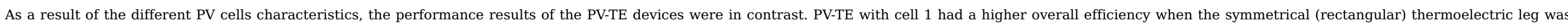

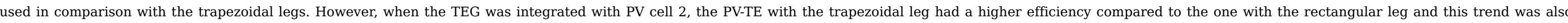
observed in the STEG. Therefore, the optimum results for STEG cannot be used as a reference for the PV-TE directly as the PV cell characteristics need to be considered.

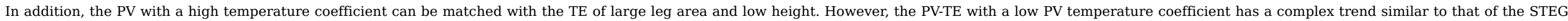

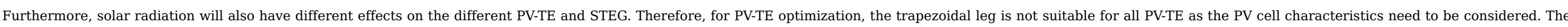
main conclusions from this study can therefore be summarized as;

1. The optimum thermoelectric geometry in a hybrid PV-TE device using Cell 1 is the same with that of the STEG and this geometry is obtained when $R_{A}=2$ (inverted trapezoid leg),

2. In contrast, the optimum thermoelectric geometry in a hybrid PV-TE device using Cell 2 is symmetrical $R_{A}=1$ (rectangular leg).

3. The optimization results for a stand-alone STEG cannot be directly referenced by the PV-TE device due to the influence of the PV cell characteristics on the overall performance.

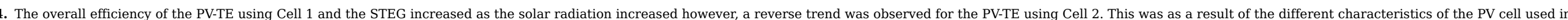
each device.

\section{Acknowledgment}

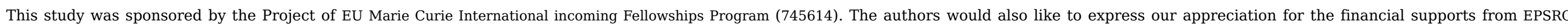

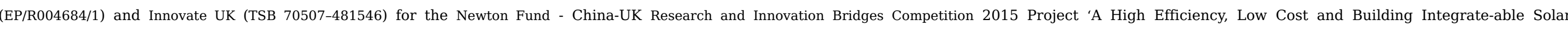
Photovoltaic/Thermal (PV/T) system for Space Heating, Hot Water and Power Supply' and DongGuan Innovation Research Team Program (No. 2014607101008). 


\section{References}

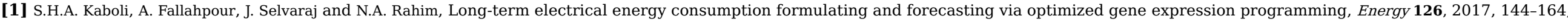
https://doi.org/10.1016/j.energy.2017.03.009.

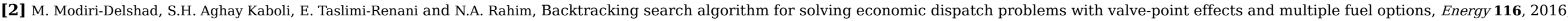
637-649, https://doi.org/10.1016/j.energy.2016.09.140.

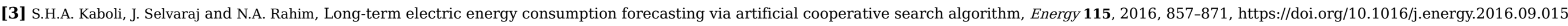

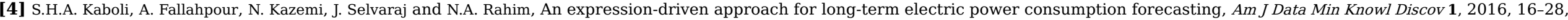
https://doi.org/10.11648/j.ajdmkd.20160101.13.

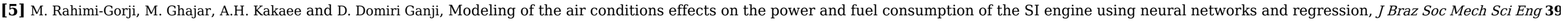
2017, 375-384, https://doi.org/10.1007/s40430-016-0539-1.

[6] N. Ahmed, N. Ali Shah, B. Ahmad, S.I.A. Shah, S. Ulhaq and M.R. Gorji, Transient MHD convective flow of fractional nanofluid between vertical plates, J Appl Comput Mech 2018, https://doi.org/10.22055/jacm.2018.26947.1364.

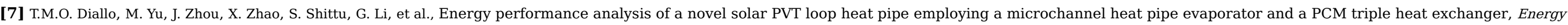
167, 2019, 866-888 https://doi.org/10.1016/j.energy.2018.10.192.

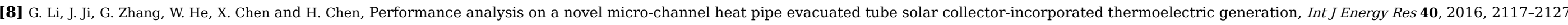
https://doi.org/10.1002/er.3589.

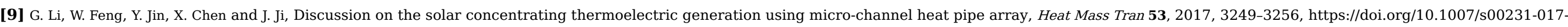
2026-3.

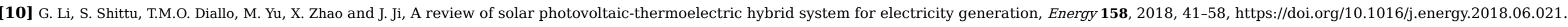

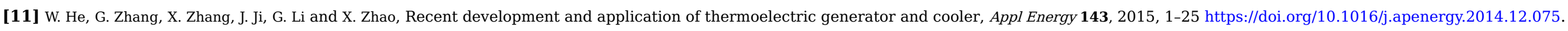

[12] A.Z. Sahin and B.S. Yilbas, The thermoelement as thermoelectric power generator: effect of leg geometry on the efficiency and power generation, Energy Convers Manag 65, 2013, 26-32, https://doi.org/10.1016/j.enconman.2012.07.020.

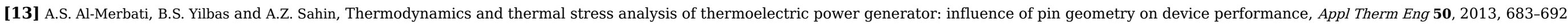
https://doi.org/10.1016/j.applthermaleng.2012.07.021.

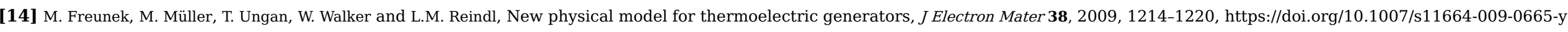

[15] A. Rezania, L.A. Rosendahl and H. Yin, Parametric optimization of thermoelectric elements footprint for maximum power generation, J Power Sources 255, 2014, 151-156, https://doi.org/10.1016/j.jpowsour.2014.01.002.

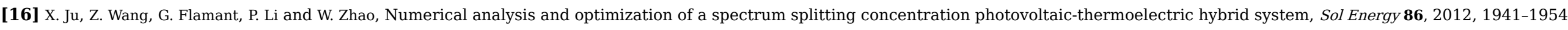
https://doi.org/10.1016/j.solener.2012.02.024.

[17] G. Li, X. Zhao and J. Ji, Conceptual development of a novel photovoltaic-thermoelectric system and preliminary economic analysis, Energy Convers Manag 126, 2016, 935-943, https://doi.org/10.1016/j.enconman.2016.08.074. 
[18] G. Li, K. Zhou, Z. Song, X. Zhao and J. Ji, Inconsistent phenomenon of thermoelectric load resistance for photovoltaic-thermoelectric module, Energy Convers Manag 161, 2018, 155-161, https://doi.org/10.1016/j.enconman.2018.01.079.

[19] W.G.J.H.M. Van Sark, Feasibility of photovoltaic - thermoelectric hybrid modules, Appl Energy 88, 2011, 2785-2790, https://doi.org/10.1016/j.apenergy.2011.02.008.

[20] E. Yin, Q. Li and Y. Xuan, One-day performance evaluation of photovoltaic-thermoelectric hybrid system, Energy 143, 2018, 337-346, https://doi.org/10.1016/j.energy.2017.11.011.

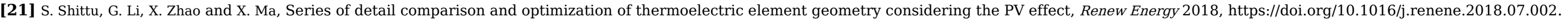

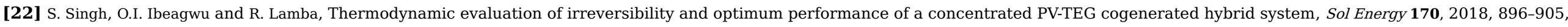
https://doi.org/10.1016/j.solener.2018.06.034.

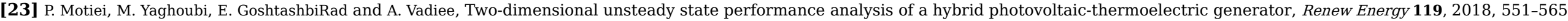
https://doi.org/10.1016/j.renene.2017.11.092.

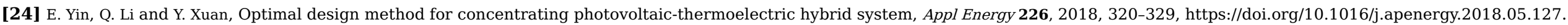

[25] C. Babu and P. Ponnambalam, The theoretical performance evaluation of hybrid PV-TEG system, Energy Convers Manag 173, 2018, 450-460, https://doi.org/10.1016/j.enconman.2018.07.104.

[26] R. Lamba and S.C. Kaushik, Solar driven concentrated photovoltaic-thermoelectric hybrid system: numerical analysis and optimization, Energy Convers Manag 170, 2018, 34-49, https://doi.org/10.1016/j.enconman.2018.05.048.

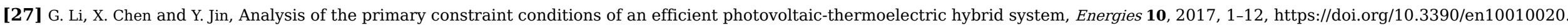

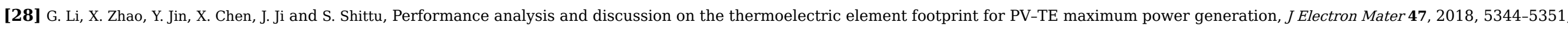
https://doi.org/10.1007/s11664-018-6421-4.

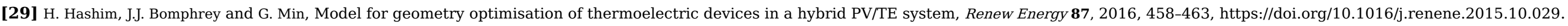

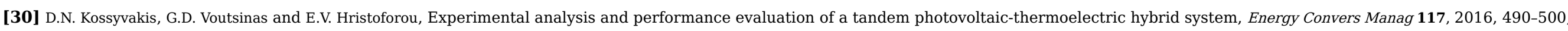
https://doi.org/10.1016/j.enconman.2016.03.023.

[31] D. Kraemer, K. McEnaney, M. Chiesa and G. Chen, Modeling and optimization of solar thermoelectric generators for terrestrial applications, Sol Energy 86, 2012, 1338-1350, https://doi.org/10.1016/j.solener.2012.01.025.

[32] W.H. Chen, C.C. Wang, C.I. Hung, C.C. Yang and R.C. Juang, Modeling and simulation for the design of thermal-concentrated solar thermoelectric generator, Energy 64, 2014, 287-297, https://doi.org/10.1016/j.energy.2013.10.073.

[33] Z. Liu, S. Zhu, Y. Ge, F. Shan, L. Zeng and W. Liu, Geometry optimization of two-stage thermoelectric generators using simplified conjugate-gradient method, Appl Energy 190, 2017, 540-552, https://doi.org/10.1016/j.apenergy.2017.01.002.

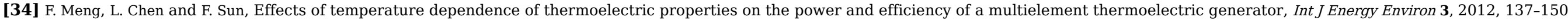

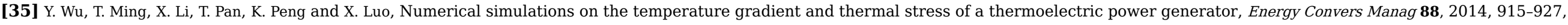
https://doi.org/10.1016/j.enconman.2014.08.069.

[36] European Thermodynamics Limited, GM250-127-14-16 Thermoelectric generator module - Datasheet, 2014, 1-4.

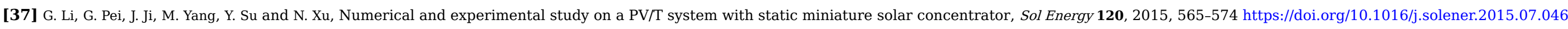

[38] J.-L. Gao, Q.-G. Du, X.-D. Zhang and X.-Q. Jiang, Thermal stress analysis and structure parameter selection for a Bi2Te3-based thermoelectric module, J Electron Mater 40, 2011, 884-888, 
https://doi.org/10.1007/s11664-011-1611-3.

[39] J.H. E. a. Wattmuff, Solar and wind induced external coefficient for solar collectors, Coop Mediterr Pour I'Energue Solaire, Rev Int d'Heliotechnique 1977, 56-60, 2nd Quart.

[40] W. He, G. Zhang, G. Li and J. Ji, Analysis and discussion on the impact of non-uniform input heat flux on thermoelectric generator array, Energy Convers Manag 98, 2015, 268-274 https://doi.org/10.1016/j.enconman.2015.04.006.

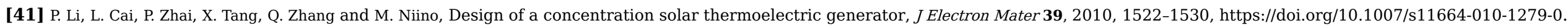

[42] J. Xiao, T. Yang, P. Li, P. Zhai and Q. Zhang, Thermal design and management for performance optimization of solar thermoelectric generator, Appl Energy 93, 2012, 33-38, https://doi.org/10.1016/j.apenergy.2011.06.006.

[43] R. Lamba and S.C. Kaushik, Modeling and performance analysis of a concentrated photovoltaic-thermoelectric hybrid power generation system, Energy Convers Manag 115, 2016, 288-298, https://doi.org/10.1016/j.enconman.2016.02.061.

[44] G. Li, X. Chen, Y. Jin and J. Ji, Optimizing on thermoelectric elements footprint of the photovoltaic-thermoelectric for maximum power generation, Energy Procedia 142, 2017, 730-735, https://doi.org/10.1016/j.egypro.2017.12.119.

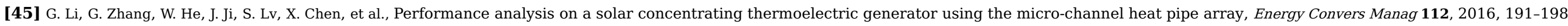
https://doi.org/10.1016/j.enconman.2016.01.025.

[46] Y.Y. Wu, S.Y. Wu and L. Xiao, Performance analysis of photovoltaic-thermoelectric hybrid system with and without glass cover, Energy Convers Manag 93, 2015, 151-159, https://doi.org/10.1016/j.enconman.2015.01.013.

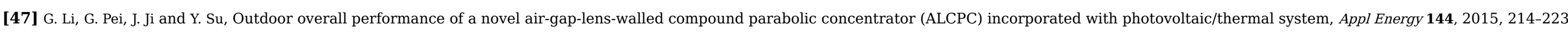
https://doi.org/10.1016/j.apenergy.2015.01.112.

\section{Highlights}

- Optimum geometry for thermoelectric in Photovoltaic-thermoelectric was presented.

- Comparison of solar thermoelectric device and Photovoltaic-thermoelectric was done.

- Three-dimensional numerical simulation using finite element method was presented.

- Two Photovoltaic cells with different thermoelectric geometries were analysed.

\section{Queries and Answers}

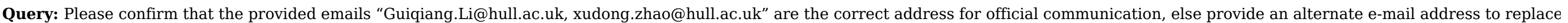
the existing one, because private e-mail addresses should not be used in articles as the address for communication.

Answer: Yes.

Query: Please check whether the order of designated corresponding authors is correct, and amend if necessary.

Answer: Yes. 


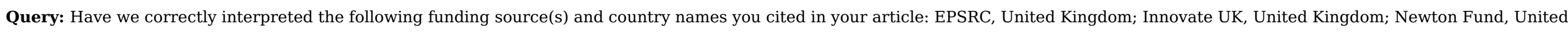
Kingdom?

Answer: Yes

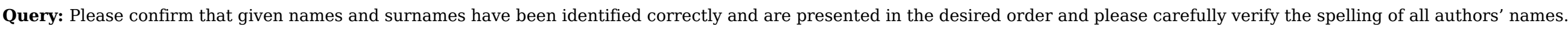
Answer: Yes

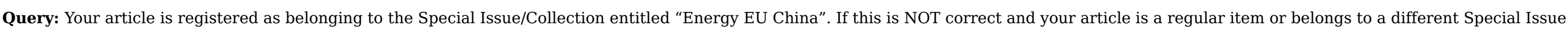
please contact s.venkiteswaran@elsevier.com immediately prior to returning your corrections.

Answer: Yes 